\title{
Fatigue life estimation of components with use a non-linear energy model coupled a finite element method
}

\author{
Abdelkrim AID ${ }^{1, *}$, Aissa ABDERRAHMANE ${ }^{1}$, Mostefa BENDOUBA $^{1}$, Abdelkader DJEBLI $^{1}$ and Mohammed El Ganaoui $^{2}$ \\ ${ }^{1}$ Laboratoire LPQ3M, B.P. 305, University of Mustapha Stambouli, Mascara, Algeria. \\ ${ }^{2}$ LERMAB - Longwy, IUT Henri Poincaré, 54400, Cosnes et Romain France
}

\begin{abstract}
The work presents a non-linear fatigue computation method together with finite element method, in which energy parameter has been used. The Proposed model has been used for simulation computations, based on experimental testing of Al-2024 aluminum alloy specimens subjected to two types of loads, i.e. variable blocs loading and random loading. Computations of energy parameter value have been done based on the results of FEM elastic-plastic analysis of cyclic properties of a material.

A computing Matlab-based algorithm of the fatigue life prediction methodology was developed. The proposed damage indicator is connected cycle by cycle to the Wöhler curve. Cycles were counted with the rain-flow algorithm, and damage was accumulated with this model and with the Palmgren-Miner rule. On the grounds of which fatigue life has been read off from only characteristics of specimens. An experimental verification shows a satisfactory agreement between the fatigue life calculation results by the proposed methodology and test results. Estimated and experimental lives are found to exhibit good agreement.
\end{abstract}

\section{1 introduction}

The mechanical components generally work under cyclic stresses with varying amplitudes during their lifetime. The fatigue phenomenon is created by these stresses and it is the major cause of failure of the mechanical components during service operation. Assessing fatigue damage is a critical issue. It is one of the most frequently encountered structural engineering problems. In general, fatigue damage cumulative theories can be classified into two categories: (1) linear damage cumulative theories and (2) nonlinear damage cumulative theories.

In order to predict the residual life of these components it is important to formulate a method to evaluate the fatigue damage accumulation. For many years, design engineers have used Palmgreen-Miner law, linear damage rule (LDR), and its modifications to predict the fatigue life of components in the case of variable loading [1]:

$$
D=\sum_{i=1}^{n} \frac{n_{i}}{N_{R i}}=\sum_{i=1}^{n} r_{i}
$$

where $n_{i}$ is the number of cycles at a given stress amplitude $\Delta \sigma_{i}, N_{R i}$ is the number of cycles to failure at the same stress amplitude and $\mathrm{D}$ is the damage variable (it is equal to 1 in correspondence of exhausted life). This method is based on the assumption of constant work absorption per cycle independent on the loading levels.

Because of the insufficiencies presented with linear damage rule (LDR), the lack of take account of the damage for stress below the limit of fatigue and lack of the interaction between levels of loading applied that can return produce a discrepancy of up an order of magnitude between the predicted and the experimented life and this calculation may be non conservative.

Many researchers have tried to modify a Miner's rule, but, due to its intrinsic deficiencies, no matter which version is used, life prediction based on this rule has been often unsatisfactory [2].

Marco and Starkey firstly proposed a non-linear load dependent damage rule [3], as follows:

$$
D=\sum_{i=1}^{n} r_{i}^{x_{i}}
$$

where $x_{i}$ is a coefficient depending on its load. This rule allows to correctly take into account the effects of different loading sequences. Experience has shown that only in some case and for some material this law, and the other theories derived from it, have shown good agreement with the experimental results; moreover the involved coefficients $\left(x_{i}\right)$ have to be calculated for each different load and load condition limiting their use in engineering applications [4].

Recently, a new approach, based on damage mechanics, has been proposed (the so called continuum damage mechanics). With the original concepts developed by Kachanov [5] and Rabotnov [6]. Chaboche and Lemaitre [7-8] applied these principles to formulate a nonlinear damage evolution equation in the form:

$$
\delta D=\left[1-(1-D)^{\beta+1}\right]^{\alpha} \cdot\left[\frac{\sigma_{a}}{M_{0}(1-D)}\right]^{\beta} . \delta n
$$

where $\beta$ and $M_{0}$ depend on material and $\sigma_{\mathrm{a}}=\sigma_{\max }-\sigma_{\mathrm{m}}$ ( $\sigma_{\max }$ and $\sigma_{\mathrm{m}}$ are respectively the maximum and the

\footnotetext{
"Corresponding author: aid_abdelkrim@univ-mascara.dz
} 
mean stress of cycle); the exponent $\alpha$ depends on the loading $\left(\sigma_{\max }, \sigma_{m}\right)$ which results in non-separability between damage and loading. The expression of $\alpha$ proposed by Chaboche is:

$$
\alpha=1-\frac{1}{H}\left\langle\frac{\sigma_{a}-\sigma_{f}}{\sigma_{u}-\sigma_{a}}\right\rangle
$$

where symbol \langle\rangle is defined as $\langle x\rangle=0$ if $x<0$ and $\langle x\rangle=x$ if $x>0$.

Many forms of the fatigue damage equation have been derived after Chaboche's work; all of them are similar in form and the main differences lie in the number and the characteristics of parameters used in the model and in the requirement for additional experiments to determine them [9-10].

The model developed by Aid et al. [11] does not require too many properties of the material and it takes into account the history of loading. This model is connected cycle by cycle with Wöhler's curve.

The experimental observations highlighted that when a positive average stress, $\sigma_{\mathrm{m}}$, is super-imposed on the cyclic loading of amplitude its, the life of the specimens decreases. The inverse effect is observed in the presence of an average stress of compression [12].

In order to take into account this phenomenon, the complementary tests can be carried out in order to establish Haigh's diagram, for life time fixed at $\mathrm{N}_{\mathrm{R}}$, the alternate stress equivalent $\sigma_{\text {aeq }}$ according to the characteristics $\left(\sigma_{\mathrm{m}}, \sigma_{\mathrm{a}}\right)$ of the cycle. This returns, in fact, to modify the curve of Wöhler for each cycle with $\sigma_{\mathrm{m}} \neq$ 0 .

The real loadings are often more complex. Estimation of fatigue life of a material subjected to random loading needs suitable calculation algorithms. In such algorithms, cycle counting [13] according to a given method (for example, the rain flow method) and damage accumulation according to the assumed hypothesis (for example Palmgren-Miner, Haigh's diagram) are the main operations.

To forecast the high-cycle fatigue life of metal material, constitutive relation of damage material and damage evolution relation can be employed by using the method of damage mechanics and introducing the damage variable. After that, the damage mechanics-finite element method can be embedded into ABAQUS by the script and subroutine based on Python and Fortran [14].

\section{Description of the model}

The strain energy density is proposed as a parameter of the fatigue analysis. The models do not include a division of the strain energy density into elastic and plastic parts, like in the case of the parameters proposed by Smith-WatsonTopper (SWT) [15], Hoffman and Seeger [16], and Bergman and Seeger [17].

For uniaxial fatigue loading, we introduce a new damage parameter, Di, defined as the ratio of the increment of energy due to stress damage over the difference between the energy due to ultimate stress and the applied stress [18]. The damage indicator is defined by:

$$
D_{i}=\frac{W_{e d i}-W_{i}}{W_{u}-W_{i}}
$$

$\mathrm{W}_{\text {edi }}$ is energy due to stress damage;

$\mathrm{W}_{\mathrm{i}}$ is energy due to the applied stress;

$\mathrm{W}_{\mathrm{u}}$ is energy due to the ultimate stress of the material.

In the first cycle, the energy due to the damage stress $\left(W_{e d}\right)$ is identical to the energy due to the applied stress $\left(W_{i}\right)$, i.e. $D_{i}=0$ and at the last cycle, the energy due to the damage stress $\left(\mathrm{W}^{\mathrm{ed}}\right)$ is equal to the energy due to the ultimate stress $\left(\mathrm{W}_{\mathrm{u}}\right)$ and therefore, $\mathrm{D}_{\mathrm{i}}=1$. The damage indicator is normalized to 1 at rupture. Damage is then translated to level $\mathrm{i}+1$ by the relations:

$$
D_{i+1}=\frac{W_{e d i}-W_{i}}{W_{u}-W_{i}}=\frac{W_{e q u i V}-W_{i+1}}{W_{u}-W_{i+1}}
$$

Where:

$\mathrm{W}_{\text {equiv }}$ is the energy due to the damage equivalent stress at level $\mathrm{i}+1$;

$\mathrm{W}_{\mathrm{i}+1}$ is the energy due to applied stress at level $\mathrm{i}+1$.

\section{Prediction of the model with bibliographic result}

Our model is now compared with recent data. They are taken from the Pavlou results [18], and from Krouse and Moore [19]. The loading conditions are illustrated in Fig. 1 .

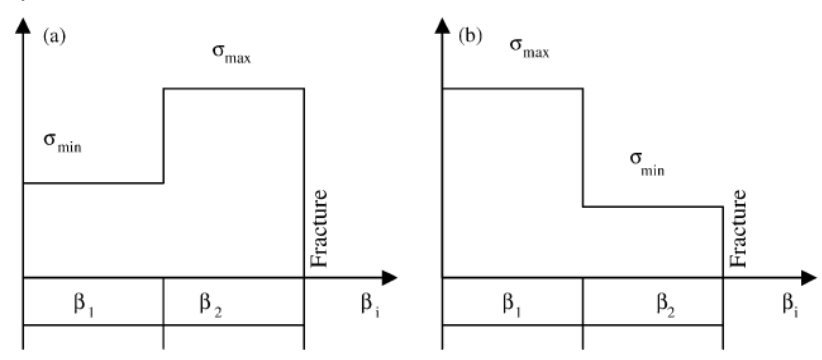

Fig. 1. Loading cycle blocks with (a) increasing amplitude, and (b) decreasing amplitude.

\subsection{Results from Pavlou [18]}

Life time for $\sigma=150 \mathrm{MPa}$ are $\mathrm{N}=430.000$ cycles and for $\sigma=200 \mathrm{MPa}$ is $\mathrm{N}=150.000$ cycles. Ultimate stress is taken

as $\sigma_{\mathrm{u}}=470 \mathrm{MPa}$.

$\beta_{1}$ fraction of life at level 1 ,

$\beta_{2}$ fraction of life at level 2 until fracture.

A comparison of experimental results, Miner and model predicted life is given in Table 1.

\subsection{Results from Krouse and Moore [19]}

Krouse and Moore got the following results for maraging 300CVM steel with material properties: yield stress $=2098 \mathrm{MPa}$ and ultimate stress 2590MPa. Number of 
cycles to failure at different stress amplitudes is given in Table 2.

Table 1: Experimental results [18], Miner and damage stress model predicted life.

\begin{tabular}{|c|c|c|c|c|c|c|c|}
\hline \multicolumn{7}{|c|}{ Increasing loading amplitude. } \\
\hline$\sigma_{1}=150 \mathrm{MPa}$ & \multicolumn{5}{|c|}{$\sigma_{2}=200 \mathrm{Mpa}, \mathrm{n}_{2}$ residual life } \\
\hline $\mathrm{n}_{1}$ & $\beta_{1}$ & \multicolumn{2}{|c|}{ Exp. } & \multicolumn{2}{c|}{ Miner } & \multicolumn{2}{c|}{ Model } \\
\cline { 3 - 8 } & & $\mathrm{n}_{2}$ & $\beta_{2}$ & $\mathrm{n}_{2}$ & $\beta_{2}$ & $\mathrm{n}_{2}$ & $\beta_{2}$ \\
\hline $86.10^{3}$ & 0.2 & 144500 & 0.96 & $12.10^{4}$ & 1 & 123485 & 0.82 \\
\hline $172.10^{3}$ & 0.4 & 133500 & 0.89 & $9.10^{4}$ & 1 & 101187 & 0.68 \\
\hline $258.10^{3}$ & 0.6 & 81700 & 0.54 & $6.10^{4}$ & 1 & 75175 & 0.50 \\
\hline
\end{tabular}

\begin{tabular}{|l|c|c|c|c|c|c|c|}
\hline \multicolumn{7}{|c|}{ Increasing loading amplitude. } \\
\hline$\sigma_{1}=200 \mathrm{MPa}$ & \multicolumn{7}{|c|}{$\sigma_{2}=150 \mathrm{Mpa}, \mathrm{n}_{2}$ residual life } \\
\hline $\mathrm{n}_{1}$ & $\beta_{1}$ & \multicolumn{2}{|c|}{ Exp. } & Miner & \multicolumn{3}{|c|}{ Model } \\
\cline { 3 - 8 } & & $\mathrm{n}_{2}$ & $\beta_{2}$ & $\mathrm{n}_{2}$ & $\beta_{2}$ & $\mathrm{n}_{2}$ & $\beta_{2}$ \\
\hline $3.10^{4}$ & 0.2 & 228700 & 0.67 & $344.10^{3}$ & 1 & 297550 & 0.69 \\
\hline $6.10^{4}$ & 0.4 & 101050 & 0.24 & $258.10^{3}$ & 1 & 19106 & 0.44 \\
\hline $9.10^{4}$ & 0.6 & 76050 & 0.18 & $17210^{3}$ & 1 & 10402 & 0.24 \\
\hline
\end{tabular}

Table 2: Number of cycles to failure at different stress amplitudes [19].

\begin{tabular}{|c|c|c|c|c|}
\hline $\begin{array}{c}\text { Stress } \\
\text { amplitude }\end{array}$ & 2086 & 2000 & 1655 & 1103 \\
\hline Fatigue life & 891 & 1160 & 3809 & 48645 \\
\hline $\begin{array}{c}\text { Stress } \\
\text { amplitude }\end{array}$ & 965 & 900 & 827 & \\
\hline Fatigue life & 112573 & 174400 & 296400 & \\
\hline
\end{tabular}

The results, for different fractions of life at the level 1 and the residual part of life at level 2 are illustrated in Fig. 4 with other experimental results [18-19].

As we can see, the deviation is lower with our model and the results are more representative than by using Miner's rule. On the experimental results given by Krouse and Moore, only one test at each loading level was performed.

\section{Specimen and experiments}

The material used in this investigation was an aluminium alloy 6082-T6. The chemical composition of the material was $(\%)$ :

$0.6 \mathrm{Mg}, 0.7 \mathrm{Si}, 0.24 \mathrm{Fe}, 0.06 \mathrm{Cu}, 0.9 \mathrm{Mn}, 0.02 \mathrm{Cr}, 0.06 \mathrm{Zn}$, and $0.02 \mathrm{Ti}$. Plane specimens, which were acquired as a plate with an $8 \mathrm{~mm}$ thick (see Fig.2).

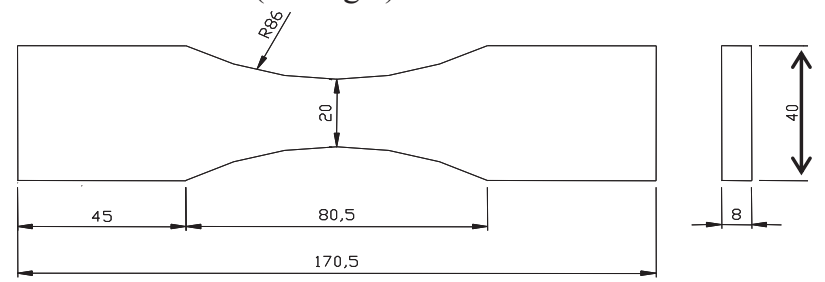

Fig.2. Geometry of a specimen.

The room temperature mechanical properties of aluminium alloy are given in Table 3 .

Table 3. Mechanical properties of the aluminium alloy.

\begin{tabular}{|c|c|c|c|}
\hline $\begin{array}{c}\text { Yielding } \\
\text { stress } \\
(\mathrm{MPa})\end{array}$ & $\begin{array}{c}\text { Ultimate } \\
\text { stress } \\
(\mathrm{MPa})\end{array}$ & $\begin{array}{c}\text { Young's } \\
\text { modulus } \\
(\mathrm{GPa})\end{array}$ & $\begin{array}{c}\text { Elongation } \\
\%\end{array}$ \\
\hline 347 & 370 & 73 & 12 \\
\hline
\end{tabular}

The experiments were carried out under uniaxial constant amplitudes for determining the Wöhler curves. An equation for the stress-life curve for the material was determined from a prior investigation, according to ASTM standards [20]:

$$
\log (\sigma)=A-m \cdot \log \left(N_{R}\right)=6.8-0,1024 \cdot \log \left(N_{R}\right)
$$

where $\sigma_{\mathrm{f}}=220 \mathrm{MPa}, \mathrm{N}_{\mathrm{G}}=2 \times 10^{6} ; \mathrm{N}_{\mathrm{R}}$ is the number of cycles to fracture, $\sigma$ is the stress amplitude, $m$ is the exponent of the Wöhler curve, $\boldsymbol{\sigma}_{\mathrm{f}}$ is the fatigue limit, and $\mathrm{N}_{\mathrm{G}}$ is the limited number of cycles corresponding to $\sigma_{\mathrm{f}}$. Four cyclic stress levels were considered and four different sequences were applied. The aim of this set of tests is to determine the influence of increasing or decreasing loading conditions on lifetime and to determinate the life fatigue under random block loading. The experimental conditions are given in table 4 .

Table 4. Experimental conditions

\begin{tabular}{|c|c|c|c|c|}
\cline { 2 - 5 } \multicolumn{1}{c|}{} & \multicolumn{4}{c|}{ Block number } \\
\cline { 2 - 5 } \multicolumn{1}{c|}{} & 1 & 2 & 3 & 4 \\
\hline$\sigma_{\max }[\mathrm{MPa}]$ & 240 & 260 & 280 & 305 \\
\hline $\mathrm{N}_{\mathrm{Ri}}$ & 412000 & 105035 & 77708 & 43800 \\
\hline
\end{tabular}

\section{Analysis of the results}

Three finite element models were used to analyze and simulate the cumulative fatigue damage using the commercial code COMSOL coupled with a matlab program. When modelling the different experimental and numerical tests carried out in uniaxial fatigue loading. The validation of a material model should be carried out in simple reproducible geometries that require a low computational cost in the FEA software. One material model validation method consists of modelling the same uniaxial tensile test from which the stress-strain data points have been recorded.

The von Mises stress contour is shown in Fig. 3 .

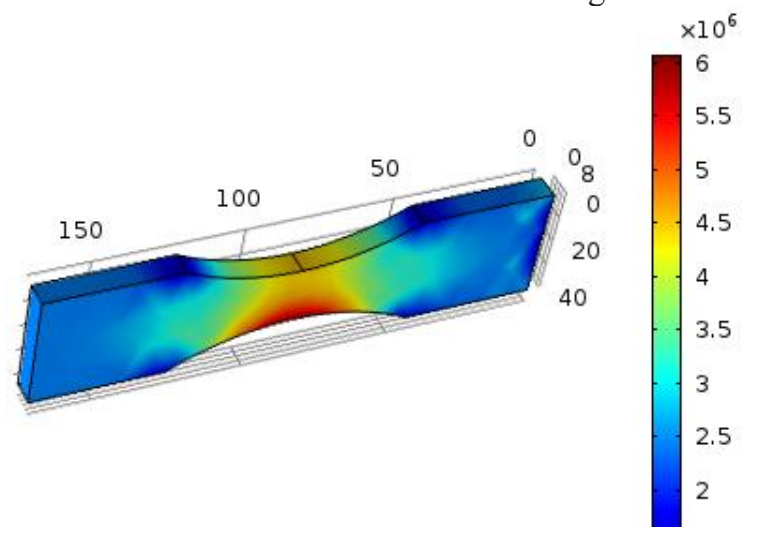

Fig. 3. Von Mises equivalent stresses.

The results of aluminium alloys 6082-T6 in cumulative damage in the different blocks loading are given in table5 [11] and represented in Fig.4. 
Table 5. Results carried out, for three configurations (increasing, decreasing and random loading)

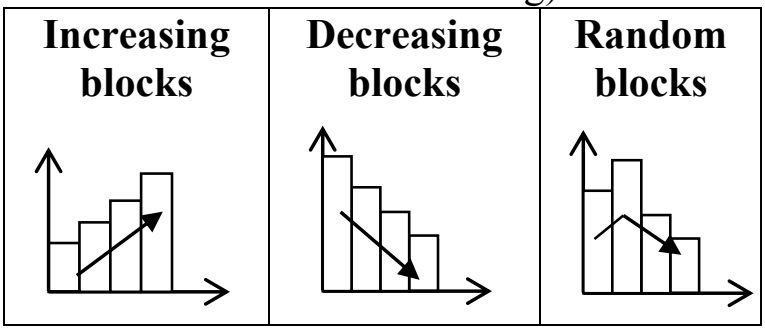

The figures $4(\mathrm{a}, \mathrm{b}, \mathrm{c})$ represent the fatigue damage evolution for three configurations (increasing, decreasing and random loading), they show the evolution of the damage according of the number of cycles of Damage Stress model and Miner's model.

In the figure 4-a, the damage evolution in Damage Stress model for all spectres is represented and also the damage evolution for Miner's model in figure 4-b.

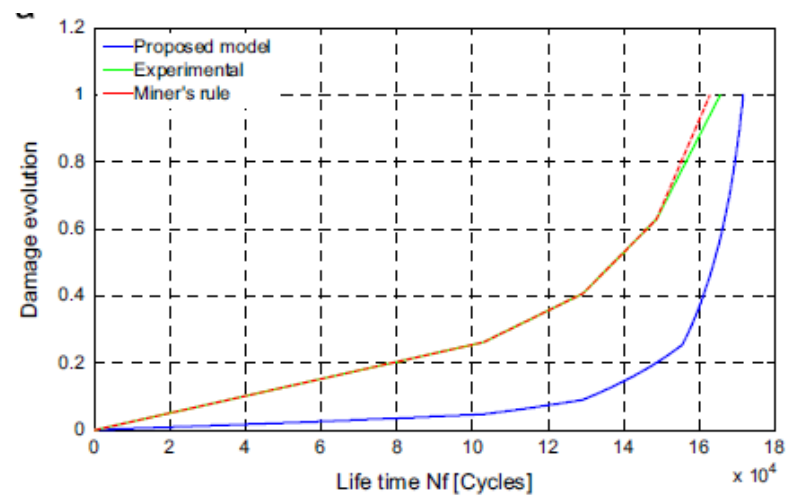

(a): increasing blocks.

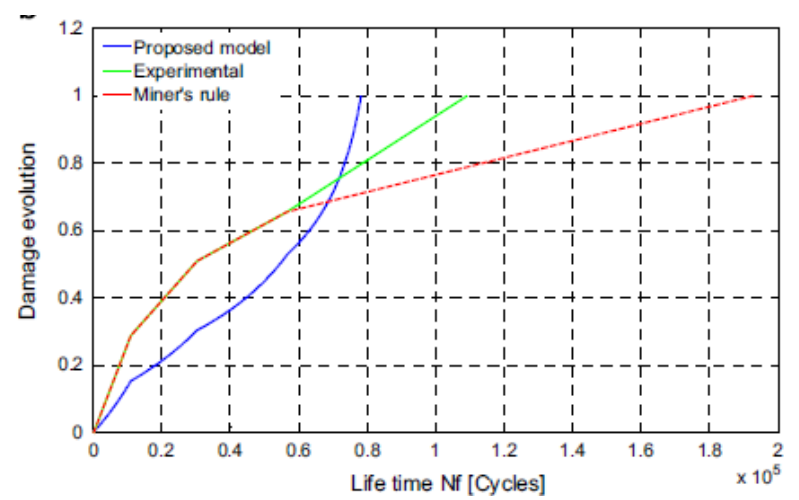

(b): decreasing blocks.

- During the totality of the lifetime of the specimens, all the curves of damage cumulative represented the model "Damage Stress" are below the curves of the Miner's rule.

- The curves of the cumulative damage determined by the proposed model have a concave form, i.e. the value of the damage remains low during the totality of the loading then believes quickly until the rupture of the specimens.

- Except the case of the figure 4-a (increasing loading), where the models give the same lifetime (at the end of the lifetime of the specimens). The decreasing and random loading configuration (Fig 4-b,4-c) shown that the model of damaged stress presents a weak variation in comparison with the Miner's model.

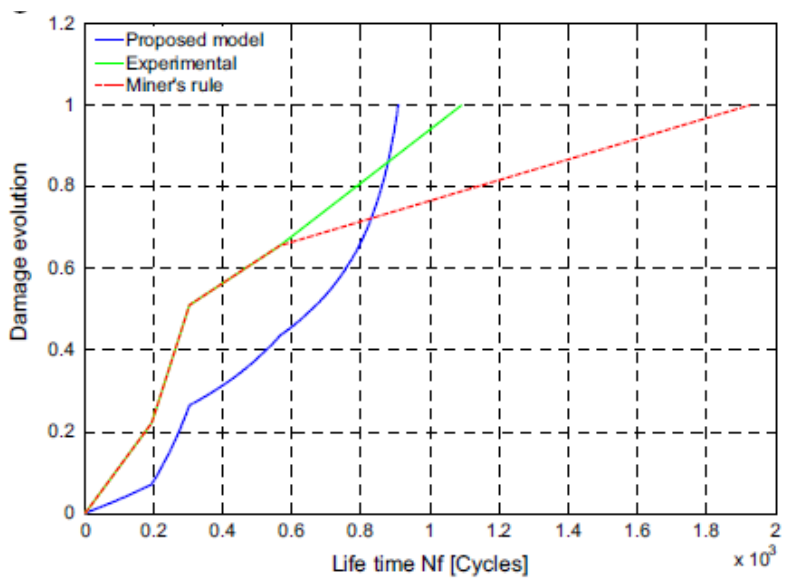

(c): random blocks loading.

Fig.4. Fatigue damage evolution with number of cycles for four sequences of loading.

-We notice in the figure 4-b and 4-c, the permutation of the first two blocks does not have an influence of the lifetime especially for the Miner's model.

- In these two last cases, the model "damaged stress" presents a good evaluation of the lifetime (variation $=2 \%$ for the decreasing configuration and variation $=41,3 \%$ for the random configuration) compared with Miner's model (variation $=159 \%$ in the first case and variation $=213,4 \%$ in the second case).

The Fig. 5 show the predicted results from the Miner's model who takes the value of 1 and the predicted indicator of the damaged stress in this study with the bibliographic results [18-19] and our results.

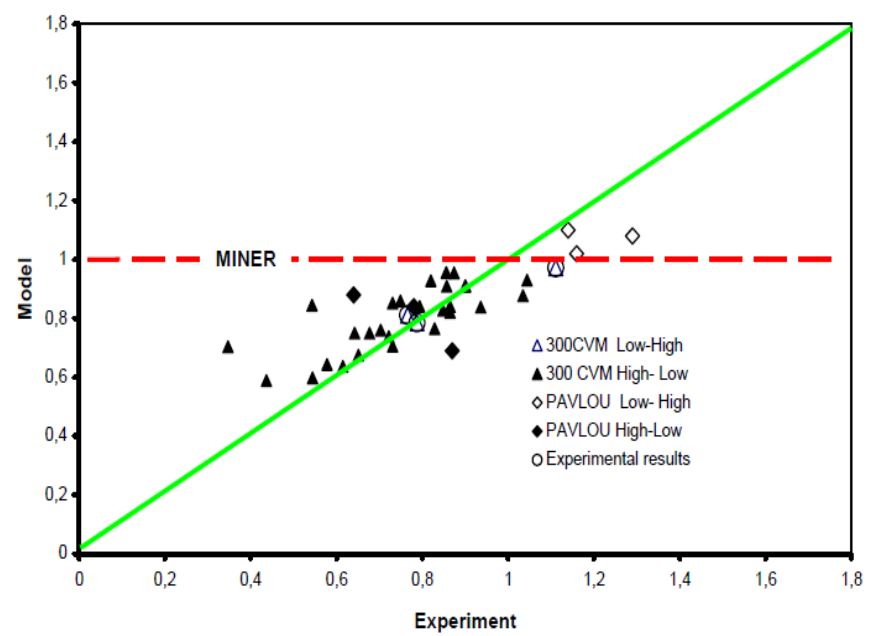

Fig. 5. Comparison of experimental results, experimental results given in [18-19] and prediction by proposed model.

This result is shown that the proposed indicator gives a good prediction in comparison with the Miner's model. 


\section{Conclusions}

The finite element approach was used for modelling and simulation. Comparison of the FEA predicted data and experimentally data supports the following conclusions:

1. The requirement for accuracy prediction applies to the aspects of loads and boundary conditions in order to generate the necessary stress and strain results.

2. This study has highlighted the need for experimental work to validate FEA modelling and to allow its advantages be maximised.

3. A nonlinear fatigue damage cumulative model is proposed, which consider the effects of the ultimate stress, data on lifetime taken by the S-N curve of the metal studied and the effect of the loading sequence are also included. The uniaxial fatigue damage evolution equation is derived, which the better descriptive ability is achieved for fatigue damage evolution by experimental verifications.

4. The application of the proposed uniaxial fatigue damage cumulative model is discussed, and the recurrence formula is derived from this model under multilevel loading. The loading case below the fatigue limit is also considered.

5. Using the Miner's rule to calculate the cumulative lifetime, we found that in all cases, increasing, decreasing and random blocks loading, the experimental results were below prediction.

6 . The results obtained by the model of the damage stress are compared with the experimental results and a good agreement has been found.

\section{References}

1. M.A.Miner, J Appl Mech 67 (1945).

2. A. Fatemi and L. Yang, Int J Fatigue 20 (1998).

3. Marco SM, Starkey WL, Trans ASME (1954).

4. V. Dattoma, S. Giancane, R. Nobile, F.W. Panella, Int J Fatigue 28 (2005).

5. Kachanov LM. Dordrecht: Martinus Nijhoff; 1986.

6. Rabotnov YN. Amsterdam: North Holland, (1969).

7. Chaboche JL. Nucl Eng Des, (1981).

8. Lamaitre J, Chaboche JL. Cambridge, UK: Cambridge University Press, (1990).

9. Shang DG, Yao WX. Int J Fatigue (1999).

10. Cheng G, Plumtree A. Int J. Fatigue 20, (1998).

11. A. Djebli, A. Aid, M. Bendoub, A. Amrouche, M. Benguediab, N. Benseddiq, Int. J. Non-Linear Mech. 51 (2013).

12. X. Pitoiset, Thèse de doctorat, Université Libres de Bruxelles (2001).

13. C. Amzallag, J.P. Gerey, J.L. Robert and J. Bahuaud, Int. J. Fatigue 16 (1994).

14. M. Wang, Q. Fei, and P. Zhang, Advances in Materials Science and Engineering (2016).

15. K.N. Smith, P. Watson, T.H. Topper, Journal of Materials 5 (4) (1970).
16. H. Hoffman, T. Seeger, in: G.E. Leese, D. Socie (Eds.), Multiaxial Fatigue: Analysis and Experiments AE-14, Society of Automative Engineers, Inc, Warrendale, USA, (1989).

17. J. Bergman, T. Seeger, in: Proceedings of the 2 nd European Conference on Fracture, Darmstadt, Germany, VDI-Report of Progress, vol. 18 (6), (1979).

18. Pavlou DG. Eng Struct 24, (2002).

19. Krouse, Moore, ASTM STP 415 (1967).

20. ASTM E 739-91, In: Annual book of ASTM standards, vol. 03.01. Philadelphia, (1999). 